\title{
Thermal Analysis Models of Deep Borehole Heat Exchangers
}

\author{
Liang Fang, Nairen Diao, Zhukun Shao, Ping Cui, Ke Zhu, and Zhaohong Fang
}

\begin{abstract}
With the advantages of much less land demand and higher temperature available, the deep borehole beat exchanger (DBHE) gets down to a depth of 1000-3000 $m$ below the ground surface, and provides a new variance of ground-coupled heat pump systems especially for applications in cold-climate regions. Coaxial tubes, instead of U-tubes, are usually used in DBHEs. Two models are presented for DBHE thermal analysis in this paper. One follows the traditional approach based on analytical solutions and the concept of the effective borehole thermal resistance for the boreholes with coaxial tubes. The other is a numerical simulation scheme based on the FDM which takes the geothermal gradient into account. The latter features much higher efficiency in computation than most commercially-available software toolkits based on FEM. The performance of DBHEs is then assessed with parameter analyses.
\end{abstract}

\section{INTRODUCTION}

The ground-coupled heat pump (GCHP) technologies have great appeal in offering higher levels of efficiency than traditional HVAC technologies. However, penetration of the GCHP technology into the market has been hindered by its limitations such as higher capital cost, requirement of a certain land plot for installation of the ground loop and concerns over the possible heat or cold accumulation in the ground heat exchangers. The vertical Borehole Heat Exchangers (BHEs) are recognized as the most-widely-used ground heat exchanger for the GCHP system (Rees 2016). A typical borehole is normally drilled down to 40-150 m deep; a single or double U-tube is then inserted in the borehole. This traditional configuration is referred to as the shallow boreholes. The concept of Deep Borehole Heat Exchanger (DBHE) has aroused growing interests from both academic and engineering arenas in China recently. The DBHEs are usually drilled down to depths of 1000-3000 m at present. Rather than the single or double U-tube configurations commonly used in shallow GCHPs, coaxial tubes are used for DBHEs out of construction considerations. As heat carrier fluid, water flows either downward through the central pipe and then returns in the annular channel between the pipes, or in an opposite circulating process.

The DBHEs may go down much deeper below the ground surface; and temperatures at the borehole bottom could reach $60-90^{\circ} \mathrm{C}$. Therefore, they have benn considered as a desirable alternative to the traditional shallow BHEs in GCHP systems, with advantages of much less land

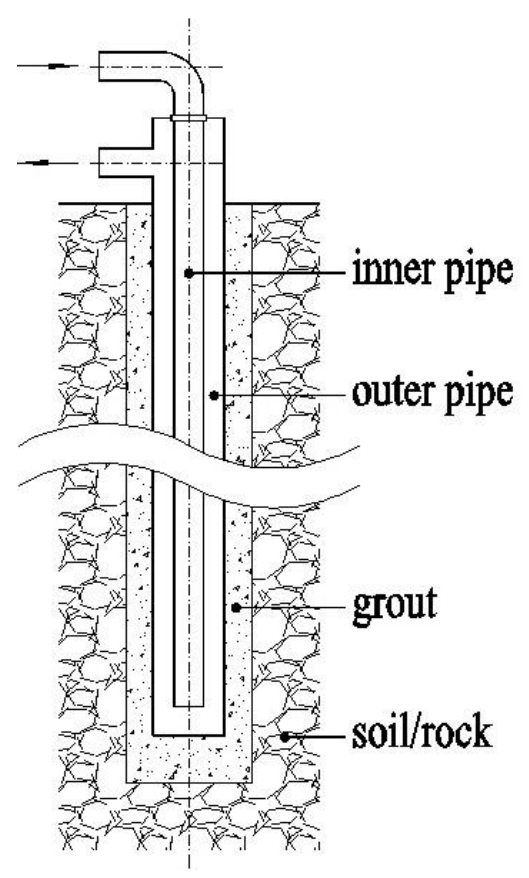

Figure 1 A diagram of a borehole with coaxial tube 
demand and higher efficiency of the heat pumps. The concept of DBHE has also arisen from the technical sector of the direct use of hydro-geothermal energy. The open hydrothermal system relies heavily on existence of hydrothermal reservoir in specific locations as well as feasibility of recharging the effluent geothermal water back to its original stratum to ensure sustainable exploitation. When no hydrothermal reservoir is found down to a certain depth of strata, or when recharging is not feasible technically or economically, the closed system of DBHE becomes an alternative. The DBHE may also be employed for the purpose of seasonal thermal storage owing to its favorable features of flexibility, higher temperature available and huge storage capacity in limited land plots. A borehole with a coaxial tube is schematically shown in Figure 1.

In spite of its advantages, application of the DBHE in GCHP systems has been out of consideration for its much higher initial drilling cost. However, an abundant surplus deep-drilling capacity in China, which used to serve for oil production, lowers the drilling cost substantially and makes the DBHE application possible. The DBHE is still realatively a new concept, and its technical feasibility and economic competitiveness need to be assessed before its practical applications. It is crucial to develop adequate and convenient means for thermal analysis of the DBHE. An idea is to apply the existing theories and tools of the shallow BHEs to thermal analyses of the DBHE. The two processes of shallow and deep BHEs, however, have a few fundamental distinctions. A uniform initial temperature in the ground is usually assumed in heat transfer models for the shallow boreholes in view of the limited depth of shallow BHEs and limited temperature difference in the longitudinal direction (Lamarche et al. 2010). It seems unreasonable, however, to ignore the geothermal gradient in DBHEs, which constitutes a key factor of their performance. Besides, there are few reports on study of the borehole with the coaxial tubes owing to its rare applications in the shallow BHEs. Beier et al. (2013) has studied the heat transfer in coaxial borehole without intaking into account the geothermal gradient. Numerical models based on FDM with a traditional solution algorithm have been developed by Holmberg et al. (2016) and Dijkshoorn et al. (2013) to study the coaxial BHE. In this study, we explored the DBHE heat transfer with these important features taken into account. An analytical model and a numerical model presented in our recent publications (Fang et al. 2017 and 2018) are compared here, and their respective merits and aplicabilities are disscussed.

\section{THERMAL RESISTANCE OF BOREHOLES WITH COAXIAL TUBES}

There have been numerous methods proposed for calculating the effective borehole thermal resistance (Javed and Spitler 2016), most of which deal with the U-tube boreholes. In the traditional approaches of BHE heat transfer analysis the effective borehole thermal resistance can be defined as

$$
R_{b}=\left(T_{f}-T_{b}\right) / q_{b}
$$

where $T_{f}$ is the mean temperature of the fluid, i.e. the average of its inlet and outlet temperatures, and $T_{b}$ is the borehole wall temperature and $q_{b}$ the specific heat load. The work presented in this section is to develop an adequate model of heat transfer in coaxial tube boreholes. The traditional approach of BHE analysis on basis of the analytical solutions could be used for the coaxial tube boreholes. The advantages of such an approach are its mature framework and high computational efficiency. Nevertheless, an inherent defect remains that simplifying assumptions are necessary, such as uniform temperature distribution along the borehole wall. The distortion in the temperature responses caused by such a simplification can be assessed by models with higher fidelity such as the numerical model presented in the next section.

It is important to realize that heat transfer inside the borehole is affected by thermal short-circuit, that is, heat transfer between the upward- and downward-flowing fluids of the heat exchanger. Taking thermal short-circuit into account, Hellström (1991) derived relationships between the effective borehole thermal resistance and the local borehole thermal resistance for single U-tube boreholes. Zeng et al. (2003) have developed the methodology and studied effective borehole resistance of double U-tubes in detail. A recent study has been reported by the authors on the effective borehole resistance of coaxial tube boreholes (Fang et al. 2017). An improved version of the study is briefly presented below.

\section{MODEL ASSUMPTIONS}

Following analysis will focus on heat transfer inside the borehole with coaxial tubes. To keep the problem 
analytically manageable, some simplifications are assumed as in discussions of the U-tube boreholes (Javed et al. 2016). They are as follows.

The heat capacity of the materials inside the borehole is neglected.

The heat conduction in the grout, pipes and fluid along the depth direction is neglected.

The borehole wall temperature, $T_{b}$, is uniform along its depth, but may vary with time.

The local thermal resistance between the upward- and downward-flowing fluids and that between fluid in the annular channel and borehole wall can be determined easily on basis of the traditional heat transfer principle, those are

$$
\left\{\begin{array}{c}
R_{1}=\frac{1}{2 \pi k_{b}} \ln \left(\frac{r_{b}}{r_{1 o}}\right)+\frac{1}{2 \pi r_{1 i} h_{1}}+\frac{1}{2 \pi k_{p 1}} \ln \left(\frac{r_{1 o}}{r_{1 i}}\right) \\
R_{2}=\frac{1}{2 \pi r_{2 i} h_{2}}+\frac{1}{2 \pi k_{p 2}} \ln \left(\frac{r_{2 o}}{r_{2 i}}\right)+\frac{1}{2 \pi r_{2 o} h_{1}}
\end{array}\right.
$$

where $k_{b}, k_{p 1}$ and $k_{p 2}$ are thermal conductivity of the grout and outer and inner pipes; $r_{b}$ is the radius of the borehole, $r_{i}$ and $r_{o}$ are the inner and outer radiuses of the pipe; $h_{1}$ and $h_{2}$ are the convective heat transfer coefficients of the annular channel and inner tube, respectively. These convective heat transfer coefficients may be counted with correlation formula provided in heat transfer handbooks.

\section{MATHEMATICAL MODEL AND SOLUTION}

It is noticed that different flow configurations, i.e. fluid entering the borehole in the annular channel and returning from the inner tube or in a reverse cycle, will lead to different fluid temperature profiles in the tubes. Therefore, both the flow configurations are discussed below. Here the mass flow rate of fluid is denoted in $M$, and its specific heat in $c$.

Flow configuration of fluid entering in the annulus and returning from the inner tube. The heat conservation of fluid in the tubes leads to the following equations when the fluid flows downward in the annular channel, and when the $\mathrm{z}$-axis is set downward.

$$
0 \leq \mathrm{z} \leq \mathrm{H}\left\{\begin{array}{c}
-M c \frac{d T_{f 1}(\mathrm{z})}{d z}=\frac{T_{f 1}(z)-T_{f 2}(z)}{R_{2}}+\frac{T_{f 1}(z)-T_{b}}{R_{1}} \\
M c \frac{d T_{f 2}(z)}{d z}=\frac{T_{f 2}(z)-T_{f 1}(z)}{R_{2}}
\end{array}\right.
$$

The boundary conditions are: $z=0 \quad T_{f 1}=T_{f}^{\prime} ; z=H \quad T_{f 1}=T_{f 2}$. Here $T_{f}^{\prime}$ is the inlet temperature of the circulating fluid, $H$ denotes the borehole depth. Equation (3) is a set of ordinary differential equations, and can be solved by Laplace transformation (Diao \& Fang 2006). Introduce the dimensionless parameters: $\theta_{1}=\left(T_{f 1}(z)-T_{b}\right) /\left(T_{f}^{\prime}-T_{b}\right)$, $\theta_{2}=\left(T_{f 2}(z)-T_{b}\right) /\left(T_{f}^{\prime}-T_{b}\right), R_{1}^{*}=M c R_{1} / H, R_{2}^{*}=M c R_{2} / H, Z=z / H$, solution of the fluid temperature distributions may be expressed in dimensionless form as

$$
\left\{\begin{array}{l}
\theta_{1}(Z)=\exp \left(-\frac{Z}{2 R_{1}^{*}}\right)\left[f_{1}(Z)+f_{2}(Z) \frac{2 \beta R_{1}^{*} \operatorname{ch}(\beta)-\operatorname{sh}(\beta)}{2 \beta R_{1}^{*} \operatorname{ch}(\beta)+\operatorname{sh}(\beta)}\right] \\
\theta_{2}(Z)=\exp \left(-\frac{Z}{2 R_{1}^{*}}\right)\left[-f_{2}(Z)+f_{3}(Z) \frac{2 \beta R_{1}^{*} \operatorname{ch}(\beta)-\operatorname{sh}(\beta)}{2 \beta R_{1}^{*} \operatorname{ch}(\beta)+\operatorname{sh}(\beta)}\right]
\end{array}\right.
$$

where $\mathrm{f}_{1}(Z)=\operatorname{ch}(\beta Z)-\frac{1}{\beta}\left(\frac{1}{2 R_{1}^{*}}+\frac{1}{R_{2}^{*}}\right) \operatorname{sh}(\beta Z), \mathrm{f}_{2}(Z)=\frac{1}{\beta R_{2}^{*}} \operatorname{sh}(\beta Z), \mathrm{f}_{3}(Z)=\operatorname{ch}(\beta Z)+\frac{1}{2 \beta}\left(\frac{1}{R_{1}^{*}}+\frac{2}{R_{2}^{*}}\right) \operatorname{sh}(\beta Z)$ and $\beta=\sqrt{\left(\frac{1}{2 R_{1}^{*}}\right)^{2}+\frac{1}{R_{1}^{*} R_{2}^{*}}}$. And a simple expression of the outlet temperature of the fluid is obtained as

$$
\theta_{f}^{\prime \prime}=\theta_{2}(0)=\frac{2 \beta R_{1}^{*} \operatorname{ch}(\beta)-\operatorname{sh}(\beta)}{2 \beta R_{1}^{*} \operatorname{ch}(\beta)+\operatorname{sh}(\beta)}
$$

Flow configuration of fluid entering in the inner tube and returning from the annulus. When the fluid flow is arranged in the opposite direction, i.e. downwards in the inner tube, the convective terms in the equations change their signs.

$$
0 \leq \mathrm{z} \leq \mathrm{H}\left\{\begin{array}{c}
M c \frac{d T_{f 1}(z)}{d z}=\frac{T_{f 1}(z)-T_{f 2}(z)}{R_{2}}+\frac{T_{f 1}(z)-T_{b}}{R_{1}} \\
-M c \frac{d T_{f 2}(z)}{d z}=\frac{T_{f 2}(z)-T_{f 1}(z)}{R_{2}}
\end{array}\right.
$$


Accordingly, the boundary conditions become $z=0 \quad T_{f 2}=T_{f}^{\prime} ; \quad z=H \quad T_{f 1}=T_{f 2}$. With the same dimensionless parameters defined as above, the fluid temperature distributions can be obtained in the dimensionless form as

$$
0 \leq \mathrm{z} \leq \mathrm{H}\left\{\begin{array}{l}
\theta_{1}(Z)=\exp \left(\frac{Z}{2 R_{1}^{*}}\right)\left[-f_{2}(Z)+f_{3}(Z) \frac{2 \beta R_{1}^{*} \operatorname{ch}(\beta)-\operatorname{sh}(\beta)}{2 \beta R_{1}^{*} \operatorname{ch}(\beta)+\operatorname{sh}(\beta)}\right] \\
\theta_{2}(Z)=\exp \left(\frac{Z}{2 R_{1}^{*}}\right)\left[f_{1}(Z)+f_{2}(Z) \frac{2 \beta R_{1}^{*} \operatorname{ch}(\beta)-\operatorname{sh}(\beta)}{2 \beta R_{1}^{*} \operatorname{ch}(\beta)+\operatorname{sh}(\beta)}\right]
\end{array}\right.
$$

And the outlet temperature of the fluid turns to be identical as in the other configuration, i.e.

$$
\theta_{f}^{\prime \prime}=\theta_{1}(0)=\frac{2 \beta R_{1}^{*} \operatorname{ch}(\beta)-\operatorname{sh}(\beta)}{2 \beta R_{1}^{*} \operatorname{ch}(\beta)+\operatorname{sh}(\beta)}
$$

It can be seen from Equations (4) and (7) that the different flow configurations lead to different temperature profiles in the tubes, but result in the identical outlet temperature of the fluid on the condition of uniform temperature distribution along the borehole wall. This also means that the different flow configurations do not influence on the effective borehole thermal resistance and the BHE performance on the same condition.

Borehole Thermal Resistance. The effective borehole resistance of the coaxial tube boreholes can be determined according to the analytical solutions of fluid temperature profiles (Diao \& Fang 2006; Fang et al. 2017), which takes the expression

$$
R_{b}=\frac{H}{2 M c} \cdot \frac{1+\theta_{f}^{\prime \prime}}{1-\theta_{f}^{\prime \prime}}=\frac{R_{1}}{2} \beta c t h(\beta)
$$

\section{NUMERICAL SOLUTION OF DBHE HEAT TRANSFER BASED ON FDM}

\section{Modeling Consideration}

It is realized that the geothermal gradient in subsurface caused by the geothermal flux plays a key role in DBHE performance, and should not be ignored. This ristricts various approaches of analytical solution; and schemes with numerical solutions have been proved potent for such tasks. Different numerical models on BHE heat transfer have also been presented over the past decades. Recent studies on heat transfer in BHEs make use of commercial software packages more often, such as FLUENT (Congedo et al. 2012), FEFLLOW (Bauer et al. 2010; Welsch et al. 2016) or COMSOL (Zhao et al. 2016) and OpenGeoSys (Kong et al. 2017), which are all based on the Finite Element Method (FEM). However, the heat transfer in BHEs involves diversified spatial and temporal spans. As a result, a few hundred thousand or even millions of nodes (elements) are needed in discretization of the borehole field. The extraordinary slenderness of the DBHE aggravates the dilemma in its discretization. Therefore, innovative models and algorithms have been sought persistently for their practical exploitation for design and optimization of BHEs.

A model has been presented by the authors based on the Finite Difference Method (FDM), which incorporates the coaxial borehole with surrounding soil (Fang et al., 2018). To achieve efficient computation the model takes advantages of the specific features of the problem, these are

The subsurface surrounding the coaxial borehole can be treated as a regular domain in the cylindrical coordinates, and then the FDM can readily be used in discretizing the domain concerned.

It is appropriate and acceptable to treat the flow and convective heat transfer in the long pipes as onedimensional. As a result, the complex simulation of transient fluid dynamics and convective heat transfer inside the pipes can be greatly simplified.

A coordinate transformation is introduced to realize the variable step sizes in the radial direction.

Large spatial step sizes in the axial direction are possible in FDM scheme owing to the relatively minor temperature gradient in this direction.

An algorithm based on the chasing method is adopted to achieve direct solution of the derived algebraic equation set for the transient two-dimensional heat transfer problem without turning to time-consuming iterations (Jia and Fang 2003). 


\section{ASSUMPTIONS AND MATHEMATICAL DESCRIPTION}

This study focuses on heat transfer in a single deep borehole with coaxial tubes. Following assumptions are taken in the model.

The soil and rock surrounding the DBHE is regarded as one or a few horizontal layers of homogeneous media.

Groundwater infiltration is neglected, and pure conduction is considered as the only mechanism of heat transfer in the soil/rock.

The temperature fluctuation of the atmosphere and its influence on the top layer of the soil are ignored.

A uniform geothermal heat flux exists throughout the media.

The convective heat transport by circulating water in pipes is the dominant mechanism of heat transfer in the longitudinal direction within the borehole; conduction by grout, pipe wall and water in the borehole is neglected in this direction.

The thermal capacity of the grout, pipe wall and water in pipes is counted in the model, the temperature of grout and pipe wall, however, is assumed to be the same as the water in the same section of the pipe.

According to these assumptions the governing equations of the heat transfer in DBHE may be presented as the follows. For each layer of soil/rock, the radial symmetry is tenable, and the conduction equation takes the form

$$
\frac{1}{\mathrm{a}} \frac{\partial \mathrm{t}}{\partial \tau}=\frac{1}{\mathrm{r}} \frac{\partial}{\partial \mathrm{r}}\left(\mathrm{r} \frac{\partial \mathrm{t}}{\partial \mathrm{r}}\right)+\frac{\partial^{2} \mathrm{t}}{\partial \mathrm{z}^{2}}
$$

A new coordinate $\sigma=\ln \left(\mathrm{r} / \mathrm{r}_{\mathrm{b}}\right)$ is assigned so as to achieve a variable step size in the radial direction. The conduction equation becomes in the new coordinate system

$$
\frac{1}{\mathrm{a}} \frac{\partial \mathrm{t}}{\partial \tau}=\frac{1}{r^{2}} \frac{\partial^{2} \mathrm{t}}{\partial \sigma}+\frac{\partial^{2} \mathrm{t}}{\partial \mathrm{z}^{2}}
$$

A uniform step size in the $\sigma$-coordinate, $\Delta \sigma$, corresponds to a geometric progression of step sizes in the $\mathrm{r}$ coordinate. That is $r_{i+1} / r_{i}=r_{1} / r_{b}=\exp (\Delta \sigma)=\mu$.

The governing equations for the circulating water in the outer annulus and the central pipe are expressed respectively as

$$
\begin{gathered}
C_{1} \frac{\partial t_{f 1}}{\partial \tau}=\frac{t_{f 2}-t_{f 1}}{R_{2}}+\frac{t_{b}-t_{f 1}}{R_{1}}-M c_{f} \frac{\partial t_{f 1}}{\partial z} \\
C_{2} \frac{\partial t_{f 2}}{\partial \tau}=\frac{t_{f 1}-t_{f 2}}{R_{2}}+M c_{f} \frac{\partial t_{f 2}}{\partial z}
\end{gathered}
$$

Here $C_{1}$ and $C_{2}$ denote the heat capacity per length of flow channels $(\mathrm{J} /(\mathrm{m} \cdot \mathrm{K}))$, including water, pipe wall and grout, and can be referred to in reference (Fang et al. 2018). The local thermal resistance between the water in the annular channel and borehole wall, $R_{1}$, and that between the two streams of circulating water, $R_{2}$, can be determined with Equation (2) as in the discussion of analytical model. It should be noticed that the signs of the convective terms in Equations (12) correspond to the flow configuration of water flowing downwards through the outer annulus and returning in the inner pipe. In the case of reversed circulation the signs in front of the convective term should be changed.

The coupling conditions of the circulating water in the inner pipe and the annulus are also needed, that is

$$
\begin{aligned}
& t_{\mathrm{f} 1}=t_{\mathrm{f} 2}, \quad \mathrm{z}=\mathrm{H}, \tau \geq 0 \\
& \mathrm{t}_{\mathrm{f} 2}-\mathrm{t}_{\mathrm{f} 1}=\mathrm{Q} / \mathrm{Mc}_{\mathrm{f}}, \quad \mathrm{z}=0, \tau \geq 0
\end{aligned}
$$

The latter corresponds to the flow configuration of downward-flow in the annulus and returning in the central pipe; and a positive $Q$ means heat extraction from the subsurface. The complete settings of the initial and boundary conditions can be found elsewhere (Fang et al. 2018).

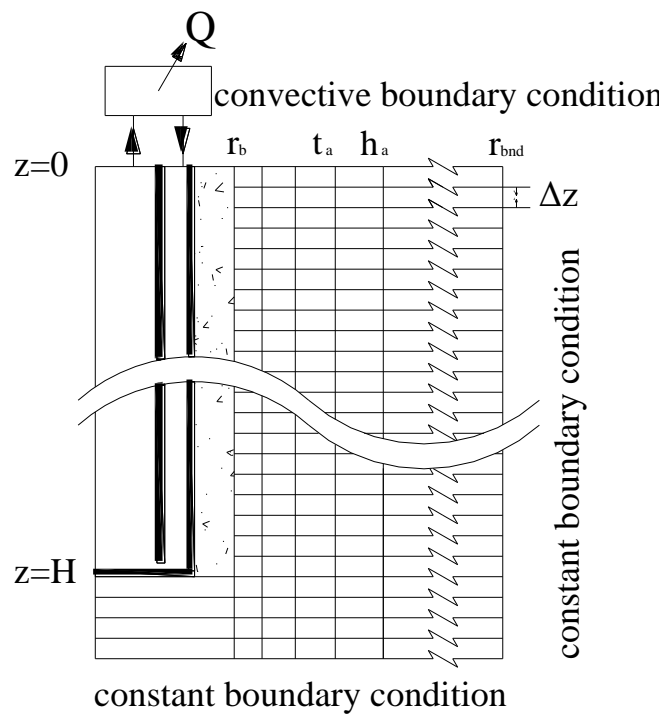

Figure 2 The discretization mesh and boundary conditions of the numerical scheme 


\section{FDM ALGORITHM}

The thermal analysis of DBHEs mainly deals with a transient two-dimensional heat conduction problem in a regular cylindrical domain, coupled with some specific convective heat transfer on one of the boundaries (borehole wall). The FDM is then chosen to solve the set of governing equations presented above. The considered domain and boundary conditions are depicted in Figure 3 together with the discretization mesh. The radial and axial coordinates are not in proportion in the diagram in consideration of extraordinary slenderness of the interested region.

An alternant time step method is used in establishing the difference equations in order to keep the unknowns in each of the derived difference equations within three. As a consequence, the algebraic equation set obtained can be solved explicitly by the chasing method without turning to time-consuming iterations. Refer to reference (Jia \& Fang, 2003) for the algorithm details.computation and simulation

\section{MODEL COMPARISON}

In order to compare the numerical scheme presented above with the analytical model, a virtual borehole is set up, served also as a benchmark of the discussion. For this case, the subsurface is assumed as a homogeneous medium; and the circulating fluid is pure water. The geothermal temperature gradient is $0.03^{\circ} \mathrm{C} / \mathrm{m}$ in this scenario. Other involved major parameters include: borehole depth and diameter, $H=2000 \mathrm{~m}, d_{b}=0.28 \mathrm{~m}$; inner and out diameters of the outer steel pipe, $d_{1}=0.188 / 0.200 \mathrm{~m}$; inner and out diameters of the inner PE pipe, $d_{2}=0.124 / 0.140 \mathrm{~m}$; thermal conductivity and diffusivity of subsurface, $k=2.5 \mathrm{~W} /(\mathrm{m} . \mathrm{K}), a=1.2 \times 10^{-6} \mathrm{~m}^{2} / \mathrm{s}$; mass flow rate of water, $M=12 \mathrm{~kg} / \mathrm{s}$, and average atmosphere temperature, $T_{a}=10^{\circ} \mathrm{C}$.

For the analytical model a uniform initial temperature in the subsurface, $T_{0}=40^{\circ} \mathrm{C}$, was assumed, equal to the mean temperature throughout the borehole depth. The line source model of transient conduction outside the borehole was employed for determining the borehole wall temperature. Then, the inlet and outlet water temperature were obtained according to the borehole thermal resistance presented above. In the numerical simulation discretization parameters were chosen as $\Delta z=10 \mathrm{~m}, \Delta \tau=180 \mathrm{~s}, \mu=1.2$, and the radial boundary was set at $\mathrm{r}_{\mathrm{bnd}}=68.9 \mathrm{~m}(\mathrm{n}=35)$. A constant heat extraction rate of $200 \mathrm{~kW}$ was set to be exerted to the DBHE for 5 months. The temperature responses of the inlet and outlet water were calculated by means of both analytical and numerical schemes, which are plotted in Figure 3.

The temperature responses obtained with the analytical and numerical schemes show similar trend as a whole, but notable quantitative difference remains. The comparison indicates that the geothermal temperature gradient plays an important role in the DBHE performance, and should not be neglected in models describing the heat transfer of the DBHEs. The analytical model with the assumption of a uniform initial temperature, however, can be calculated readily without appealing to computer, may still be useful for rough conceptual estimations.

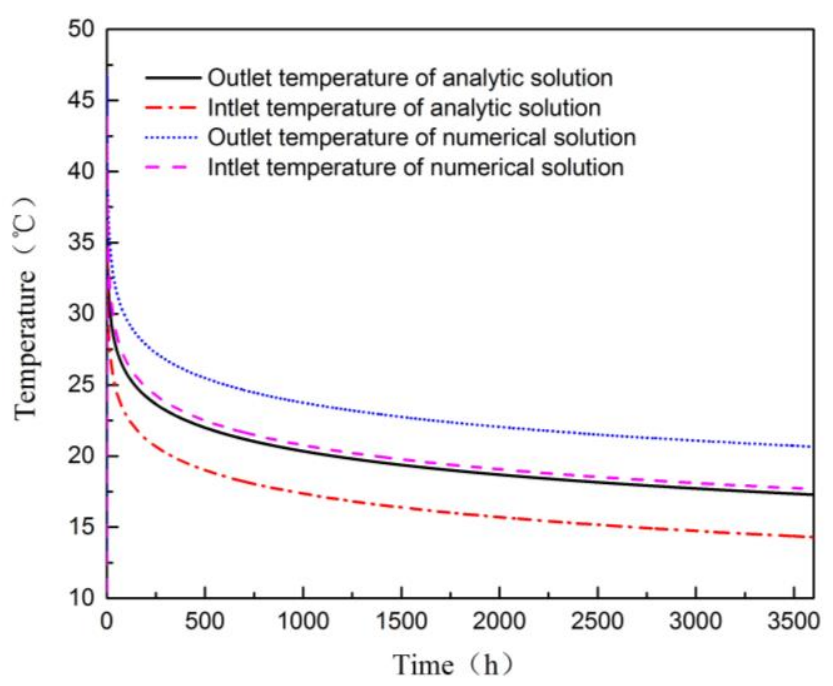

Figure 3 The water temperature responses comparison between the analytical and numerical models

\section{NOMINAL DBHE CAPACITY}

The FDM simulation scheme is then used to study performance of DBHEs. The BHEs may be referred to as a thermal-storage-type heat exchanger, and their operating status and performance depend heavily on their working history besides its geometric and physical configurations. Even though it is difficult to precisely quantify the performance or capacity of a certain borehole, a quantitative index is still desirable in parametric analyses of the BHE performance. The concept of "nominal DBHE capacity" has been suggested (Fang et al. 2018), which could be 
defined as the maximum continuous heat extraction rate that a deep borehole can undertake on the condition that the inlet temperature of the DBHE should not be less than $5^{\circ} \mathrm{C}$ at the end of heat extraction period of 3 months. The DBHE nominal capacity may be determined by means of simulation, but hardly by tests. Iteration in simulation is needed to determine the nominal DBHE capacity. This concept is used in the following discussions.

\section{PARAMETRIC STUDIES}

Different from the conclusions drawn by the analytical model where uniform temperature distribution on the borehole wall is predefined, the numerical model indicates that different flow configurations of the circulating water, i.e. flow downward in the annulus or in the central tube, not only make differences in the water temperature profiles in the tubes, but also result in different heat exchanger performance of the coaxial tube boreholes.

Parametric studies may be conducted based on the concept of nominal capacity of DBHEs. As mentioned before, higher thermal resistance of the central pipe wall is desirable to reduce the thermal short-circuit between the upward- and downward-flowing streams. These influences can be quantified by simulation, and the results obtained on the benchmark borehole are plotted in Figure 4. It shows that the thermal resistance of inner pipe affects greatly the DBHE performance. More adequate insulation between the two channels is needed to improve the heat transfer efficiency. Besides, it is clear that the flow configuration of entering in the annulus and returning through the inner pipe when extracting heat from the ground is more efficient than the opposite flow direction. While heat is injected into the ground, simulation shows that an opposite flow is better to enhance the heat transfer. Therefore, in the extraction phase, the cold water should enter the outer annulus to utilize the borehole wall as heat exchanger surface at full length. In heat injection phase, however, the water should reach the bottom of the borehole in the insulated inner pipe before discharging the bulk of its heat into the surrounding subsurface at maximum depth. Thus, seasonally alternating flow directions in the DBHE is beneficial in borehole thermal energy storage systems.

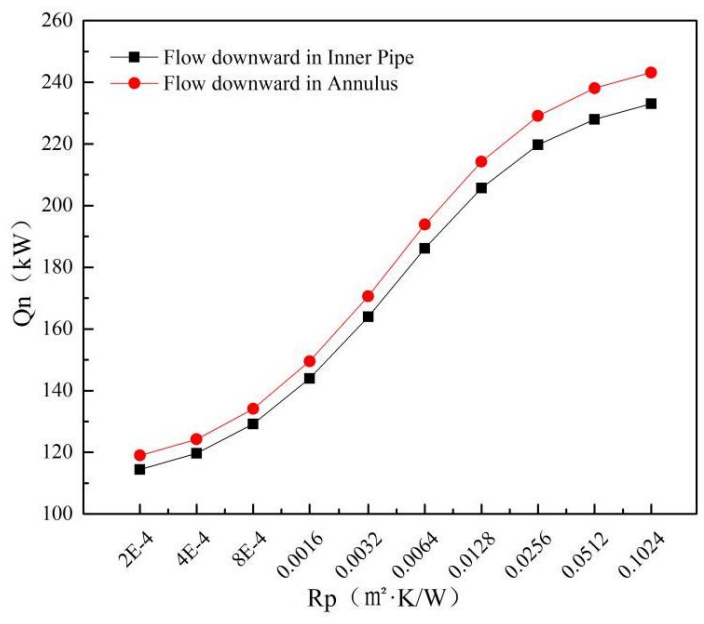

Figure 4 Nominal capacity of DBHE vs. thermal resistance of per length of inner pipe

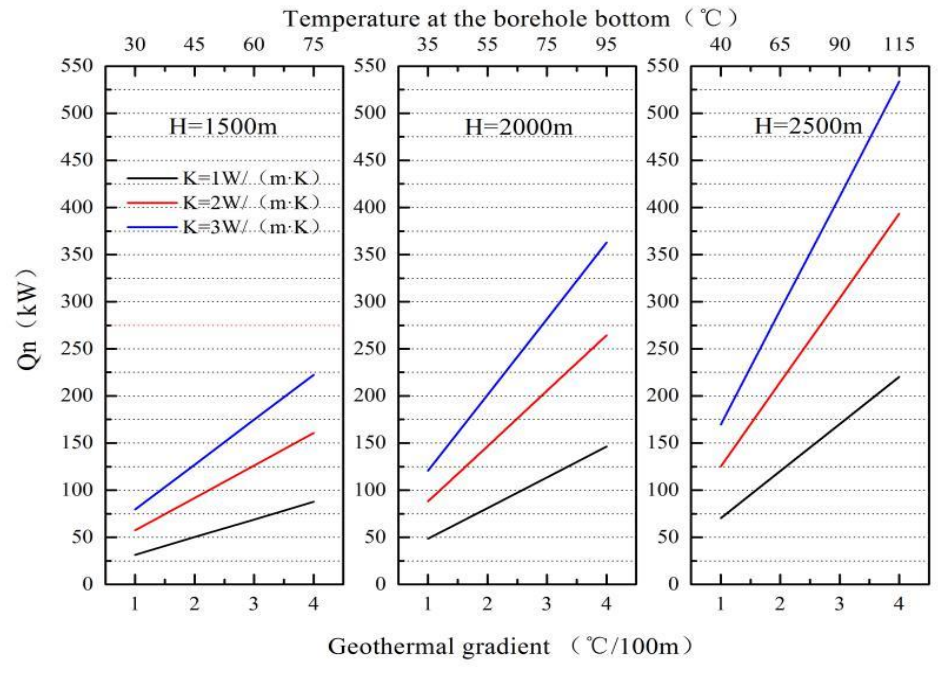

Figure 5 The DBHE nominal capacity diagram

The DBHE capacity is influenced by quite a lot of factors. The undisturbed temperature at the borehole bottom plays an important role in determination of the borehole heat extraction capacity, which depends mainly on the borehole depth, local geothermal heat flux and thermal conductivity of subsurface. The temperature difference across a certain layer of strata is proportional to the geothermal heat flux, but inversely proportional to its conductivity. Lower thermal conductivity of the subsurface will result in a higher temperature at borehole bottom when the geothermal heat flux is fixed. A diagram has been worked out on the assumption of a homogeneous subsurface (Fang et al. 2018). It is convenient for engineers to obtain an estimation of the nominal capacity of a DBHE according to the few key parameters, which is also shown in Figure 5. 


\section{PERFORMANCE SIMULATION}

The numerical FDM scheme is used to simulate the performance of a GCHP system for 10 years with the benchmark DBHE. The $8000 \mathrm{~m}^{2}$ building is located in north-eastern China, and only heating is provided in winter. The annual hourly heating load profile was calculated with a software package DeST developed in China (Yan et al., 2008; Peng et al. 2014). The heat extraction rates were determined then on the assumption of heat pump with a COP of 4.0. The parameters chosen for computation are as follows: $\mu=1.2$ for radial direction discretization, $\Delta z=10 \mathrm{~m}$, the time step is 180s. The radial boundary was set at $171.5 \mathrm{~m} \mathrm{(N=40)}$ away from the borehole center. It took 55 minutes to finish the simulation on a common laptop computer (Intel (R) Core ${ }^{\mathrm{TM}}$ i5-2450M CPU @ 2.50GHz, 4G memory). Water is arranged to flow downwards in the annular channel and return in the inner tube while extracting heat from the ground. Circulation stops when heating is off. The temperature responses show cyclic fluctuations with rapid drops in the heating seasons and significant recovery in the non-heating periods. It is also noticed that the minimum temperatures, corresponding to the maximum load in winter, become slightly lower in the first 3-5 years, but turn to quite stable in the following years. This feature is understandable because only a single DBHE is involved here. It may be inferred that the annual balance between heat extraction and injection is much less important for DBHEs located far enough from each other.

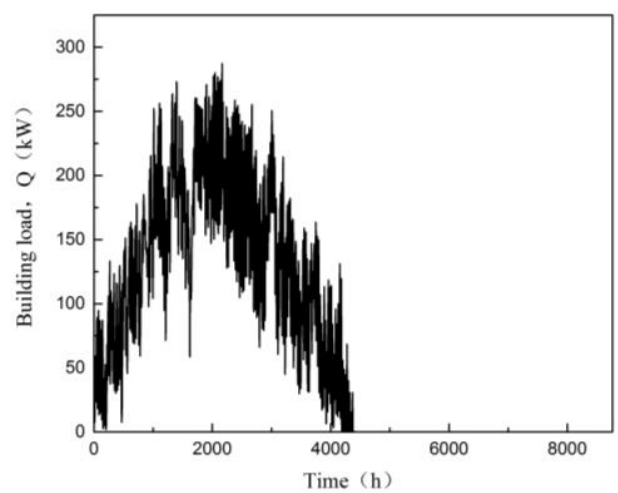

(a) Annual heating load of the building

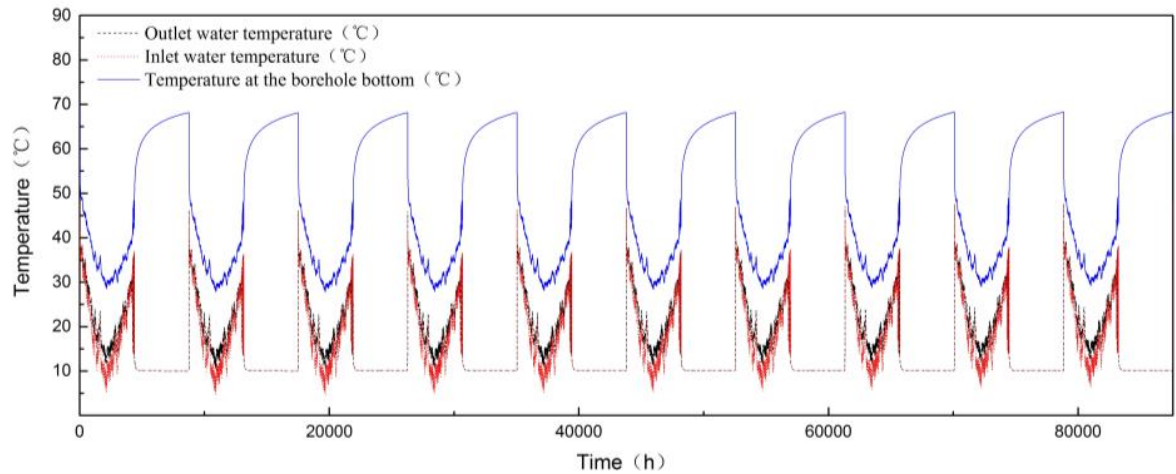

(b) The temperature responses of the inlet and outlet water as well as that at borehole bottom

Figure 6 Simulation of a DBHE operation for 10 years

\section{CONCLUSIONS}

A few conclusions have been drawn from this study.

For BHEs with coaxial tubes, analytical solutions have been derived to calculate temperature profiles in the annulus and inner tube as well as the effective borehole resistance. The solutions indicate that different configurations of the circulation directions result in different fluid temperature profiles in the tubes, but lead to the same fluid outlet temperature and borehole resistance when the temperature distribution on the borehole wall remains uniform.

Numerical simulation seems more appropriate for thermal analysis of DBHE since the geothermal gradient in subsurface could be considered adequately. While a couple of commercial softwares are available to solve complex flow and heat transfer problems, a great amount of elements (nodes) have to be dealt with in problems such as DBHEs, which results in time-consuming computations. Based on the FDM, the numerical scheme developed specifically for coaxial DBHEs in this study is proven to be computationally-efficient, and may provide a useful tool for DBHE design and optimization. Results of the simulation have shown that the configurations of the circulation directions do make difference in the DBHE performance in view of the influence of geothermal gradient. Nominal DBHE capacities are evaluated according to their key parameters such as borehole depth, subsurface conductivity and geothermal heat flux.

More DBHE geometric and physical factors need to be investigated on their impacts on DBHE performances. And economic assessment will also be essential in its feasibility study. A pilot DBHE project is under construction 
with technical assistance of this study. Real operation data will be collected to further verify the models.

\section{ACKNOWLEDGMENTS}

This work is supported by the National Natural Science Foundation of China (41702325) and Taishan Scholar Project of Shandong Province of China.

\section{REFERENCES}

Bauer, D., R. Marx, J. Nußbicker-Lux, F. Ochs, W. Heidemann and H. Müller-Steinhagen. 2010. German central solar heating plants with seasonal heat storage. Solar Energy 84(4): 612-623.

Beier, R. A., J. Acuña, P. Mogensen, B. Palm. 2014. Transient heat transfer in a coaxial borebole heat exchanger. Geothermics 51: 470-482

Beier, R. A., J. Acuña, P. Mogensen, B. Palm. 2013. Borehole resistance and vertical temperature profiles in coaxial borehole heat exchangers. Applied Energy 102: 665-675.

Congedo P.M., G. Colangelo, G. Starace. 2012. CFD simulations of horizontal ground heat exchangers: A comparison among different configurations. Applied Thermal Engineering 33-34: 24-32.

Diao, N. and Z. Fang. 2006. The ground-coupled heat pump technology (in Chinese), Science Press, Beijing.

Dijkshoorn, L., S. Speer, R. Pechnig. 2013. Measurements and Design Calculations for a Deep Coaxial Borehole Heat Exchanger in Aachen, Germany. International Journal of Geophysics: 1-14.

Fang L., Diao N., Shao Z. and Fang Z. 2017. Study on thermal resistance of coaxial tube boreholes in ground-coupled heat pump systems. Procedia Engineering 205: 3735-3742.

Fang L., N. Diao, Z. Shao, K.Zhu and Z. Fang. 2018. A computationally efficient numerical model for heat transfer simulation of deep borehole heat exchanger. Energy \& Buildings 167: 79-88.

Hellström, G., Ground heat storage - Thermal analyses of duct storage systems theory, Ph.D. thesis. Sweden: University of Lund. 1991.

Holmberg, H., J. Acuña, E. Næss and O. K. Sønju. 2016. Thermal evaluation of coaxial deep borehole heat exchangers. Renewable Energy 97: 65-76.

Javed, S., J.D. Spitler. 2016. Calculation of borehole thermal resistance. Advances in Ground-Source Heat Pump Systems. Duxford, UK: Woodhead Publishing.

Jia, L. and Z. Fang. 2003. Advanced Heat Transfer (the 2nd Edition). Beijing, China: Higher Education Press.

Kong, Y.L., C.F. Chen, H.B. Shao, Z.H. Pang, L.P. Xiong and J.Y. Wang. Principle and capacity qualification of deep borehole beat exchangers. Chinese Journal of Geophysics (in Chinese) 60(12).

Lamarche, L., S. Kajl and B. Beauchamp. 2010. A review of methods to evaluate borehole thermal resistances in geothermal heat-pump systems. Geothermics 39 (2): 187-200.

Peng, C., Wang L., Zhang X. 2014. DeST-based dynamic simulation and energy efficiency retrofitanalysis of commercial buildings in the hot summer/coldwinter zone of China: A case in Nanjing. Energy \& Buildings 78: 123-131.

Rees, S.J. 2016. An introduction to ground-sourceheat pump technology, Advances in Ground-Source Heat Pump Systems. Duxford, UK: Woodhead Publishing.

Welsch, B., W. Rühaak, D.O. Schulte, K. Bär and I. Sass. 2016. Characteristics of medium deep borehole thermal energy storage. International Journal of Energy Research 40 (13): 1855-1868.

Yan, D., Xia J., Tang Q., Song F., Zhang X., Jiang Y. 2008. DeST-An Integrated Building Simulation Toolkit Part I : Fundamentals, Build Simul 1: 95-110Zhao, Q., B. Chen and F. Liu. 2016. Study on the thermal performance of several types of energy pile ground heat exchangers: $U$-shaped, $W$-shaped and spiral-shaped. Energy and Buildings 133: 335-344.

Zeng, H., N. Diao and Z. Fang. 2003. Heat transfer analysis of boreholes in vertical ground heat exchangers. International Journal of Heat and Mass Transfer 46 (23): 4467-4481. 